\title{
Effects of Vitamin E on Transfusion Requirements in Transfusion- Dependent Beta-Thalassemia Patients
}

\author{
Duangdee Trangsuwan, M.D. ${ }^{1}$, Malai Wongchanchailert, M.D. ${ }^{1}$, Ladda Mo-suwan, M.D. ${ }^{1}$, \\ Thirachit Chotsampancharoen, M.D. ${ }^{1}$, Ruchaneekorn W. Kalpravidh, Ph.D. ${ }^{2}$, Penjamaporn Apiromruck, M. Pharm. ${ }^{3}$, \\ Thanom Chu-ngan, B.N.C. ${ }^{4}$, Sudarat Khotchawan, B.N.C. ${ }^{1}$, Sarapee Duangchu, M.Sc. ${ }^{1}$ \\ 'Department of Pediatrics, Faculty of Medicine, Prince of Songkla University, Hat Yai, Songkhla 90110, Thailand. \\ ${ }^{2}$ Department of Biochemistry, Faculty of Medicine, Siriraj Hospital, Mahidol University, Bangkok 10700, Thailand. \\ ${ }^{3}$ Pharmacy Division, ${ }^{4}$ Nursing Services Division, Songklanagarind Hospital, Faculty of Medicine, Prince of Songkla University, \\ Hat Yai, Songkhla 90110, Thailand. \\ Received 13 February 2018 • Accepted 22 May 2018 • Published online 23 August 2018
}

\section{Abstract:}

Objective: To evaluate the volume of blood transfusion requirements as well as hemolytic and oxidative biochemical variables in transfusion-dependent $\beta$-thalassemia patients supplemented with vitamin $\mathrm{E}$.

Material and Methods: A prospective, double-blind, randomized, placebo-controlled, crossover study was undertaken between December, 2012 and September, 2014 in the Pediatric Clinic of Songklanagarind Hospital. The participants were $\beta$-thalassemia major and $\mathrm{Hb} E / \beta$-thalassemia patients aged between 5 and 18 years. A random allocation sequence was generated to receiving either 6 months of vitamin $E$ or placebo followed by a 3-month washout period and then switching to another drug for 6 months. The outcome variable measurements were the volumes of the transfused packed red cells, and the hemolytic and oxidative biochemical variables.

Results: Thirty-nine patients were enrolled into the study. All of them had significantly low levels of vitamin $E$ and reduced glutathione levels, as well as high levels of oxidative stress shown by significantly high levels of malondialdehyde, superoxide dismutase, and glutathione peroxidase. The vitamin E levels became normal after the 6-month period of 200-400 milligram per day of oral vitamin E intake. All of the measured oxidative stress parameters did not improve except for the glutathione peroxidase level. Moreover, there was no difference in the volumes of transfused packed red cell requirements as well as hemolytic parameters like aspartate transaminase, lactate dehydrogenase, reticulocyte count and total bilirubin levels. Finally, no adverse reactions to oral vitamin $\mathrm{E}$ were found.

Contact: Malai Wongchanchailert, M.D.

Department of Pediatrics, Faculty of Medicine, Prince of Songkla University,

Hat Yai, Songkhla 90110, Thailand.

E-mail: malai.w@psu.ac.th
J Health Sci Med Res 2018;36(3):225-234 DOI: http://dx.doi.org/10.31584/jhsmr.2018.36.3.19

www.jhsmr.org 
Conclusion: Vitamin E supplementation normalized the vitamin E level and possibly partially reduced oxidative stress, but there was no difference in the volume of transfusion requirements or the hemolytic parameters in transfusion-dependent $\beta$-thalassemia patients.

Keywords: antioxidant, blood transfusion, hemoglobin, oxidative stress, thalassemia, vitamin E

\section{Introduction}

Thalassemia, the most common inherited hemoglobin disorder in Thailand, is caused by mutations in globin genes that result in qualitative defects (hemoglobinopathies) or quantitative defects (thalassemia syndromes) in globin synthesis, which makes up hemoglobin. The most relevant types are $\alpha$ - and $\beta$-thalassemia. ${ }^{1}$ In Thailand, about $30.0-40.0 \%$ of the population are carriers of at least one of the abnormal genes; $1.0 \%$ is affected with these diseases. ${ }^{2}$

Stem cell transplantation is the only curative treatment for the disease, but it is not feasible for everyone. ${ }^{3}$ Therefore, supportive blood transfusion is usually the principal treatment especially for transfusion-dependent thalassemias (TDTs) that include patients with $\beta$-thalassemia major and severe hemoglobin $(\mathrm{Hb})$ E/ $\beta$-thalassemia. ${ }^{4}$ The major consequence of regular blood transfusion is iron overload, which is toxic to many tissues, causing heart failure, cirrhosis, liver cancer, growth retardation and multiple endocrine abnormalities. ${ }^{4,5}$ Moreover, these iron species catalyze the Fenton reaction leading to the overproduction of reactive oxygen species (ROS) in erythrocytesespecially hydroxyl radicals and superoxide anionsoxidative damage to the protein and lipid components of cells. ${ }^{6}$ Concomitantly, $\beta$-thalassemia causes the accumulation of unpaired $\alpha$-globin, which is a potent oxidant, catalyzing the production of ROS that damages the membrane of erythroid precursors and mature erythrocytes. ${ }^{7}$ Finally, these pathophysiologies lead to peripheral hemolysis, premature apoptosis, and anemia. ${ }^{8}$

Earlier studies have shown that malondialdehyde (MDA) levels, the breakdown products of lipid peroxidation, were elevated, ${ }^{9-12}$ while antioxidants e.g., reduced glutathione (GSH), vitamin $A$, vitamin $C$ and vitamin $E$ were deficient. ${ }^{9,13}$ Moreover, enzymatic antioxidants, e.g., superoxide dismutase (SOD) and glutathione peroxidase (GPX), were found in higher levels among $\beta$-thalassemia major patients than normal controls. ${ }^{14}$ These results confirm the presence of a severe oxidative stress situation in the erythrocytes of transfusion-dependent $\beta$-thalassemia patients. ${ }^{11}$

Vitamin $\mathrm{E}$ or tocopherol is one of the most potent natural antioxidants in the body. It functions as a chainbreaking antioxidant that prevents the propagation of free radical reactions. ${ }^{15}$ The mean level of vitamin $E$ in red blood cells (RBCs) are 3 times lower in thalassemic patients, ${ }^{16}$ so the effects of vitamin $E$ supplementation in these patients have long been a topic of interest. However, most previous studies have focused on biochemical changes in terms of oxidative stress and antioxidant status. ${ }^{11,17,18}$

Das et al., found an improvement in catalase and GPx activity after a supplement of 10 milligrams per kilogram of vitamin E once daily for 4 weeks. ${ }^{11}$ Moreover, Dissayabutra et al., reported a significant increase in plasma vitamin C, vitamin E, and glutathione, and a slightly insignificant decrease in total bilirubin (TB) after a 3-months period of 100 milligrams per day of vitamin C and 400-600 milligrams per day of vitamin E supplementation. However, the levels of plasma and erythrocyte MDA, hemoglobin and plasmafree hemoglobin were not different during the study period. ${ }^{17}$ Rachmilewitz, et al. showed a decrease in the extent of erythrocyte lipid membrane peroxidation, while no significant changes occurred in hemoglobin levels and transfusion 
requirements after a daily supplement of $750-1,000 \mathrm{mg}$ of vitamin $\mathrm{E}$ for $5-7$ months in patients aged $15-30$ years. ${ }^{18}$

The benefit of vitamin $E$ in the prevention and treatment of anemia may be attributed to its ability to inhibit the oxidation of polyunsaturated fatty acids in the red cell membrane. ${ }^{15}$ This role in the reduction of red cell destruction augments the advantage of vitamin $E$ in iron-excess oxidative stress conditions as is the case in thalassemia. However, the previous studies, as mentioned above, have mostly involved small groups of patients and were mainly laboratory-relevant. Furthermore, studies on the clinical benefit of vitamin $E$ in the aspect of transfusion requirement in children are limited. Therefore, we aimed to study the effects of vitamin E supplementation on the volume of blood required for transfusions, and also the hemolytic and oxidative biochemical variables in transfusion-dependent $\beta$-thalassemia patients.

\section{Material and Methods}

This was a prospective, double-blind, randomized, placebo-controlled, crossover study that was undertaken from December 2012 to September, 2014 in the Pediatric Clinic of Songklanagarind Hospital, Thailand. Children aged between 5 and 18 years, who were diagnosed with $\beta$-thalassemia major and $\mathrm{Hb} E / \beta$-thalassemia based on hemoglobin typing and DNA mutation analysis, were included. The duration of treatment in the clinic was more than 6 months, and each patient required more than 8 transfusions a year. The eligible patients for the study were consented by their parents for baseline data, blood collection and medication. The study was approved by the Songklanagarind Hospital Ethics Committee, which follows the Good Clinical Practice Guidelines of the Helsinki Declaration, prior to its commencement.

The exclusion criteria comprised the presence of any other uncontrolled chronic disease unrelated to $\beta$-thalassemia, antioxidant or herbal medicine supplemen- tation, suspected vitamin E allergy, and being scheduled for hematopoietic stem cell transplantation.

The children were randomly assigned to receiving either vitamin $\mathrm{E}$ or a placebo for 6 months, followed by a 3-month washout period, and then switching to another drug for 6 months. The dosage of vitamin E supplemented was based on the patient's weight; the patients weighing up to $20 \mathrm{~kg}$ received $200 \mathrm{mg}$ daily, and those weighing more than $20 \mathrm{~kg}$ received $400 \mathrm{mg}$ daily.

The primary outcome for this study was the volume of transfused packed red cells required to keep the same baseline hemoglobin level during each 6-month study. There were four secondary outcomes: (a) hemolytic parameters, which were the size of the liver and spleen, the level of aspartate transaminase (AST), lactate dehydrogenase (LDH) and TB, and reticulocyte count; (b) levels of vitamin $E$ in the blood; (c) the oxidative stress parameter represented as MDA; and (d) the antioxidant status, which consisted of the levels of GSH, GPx and SOD activity.

A sample size calculation was performed prior to the commencement of the study. To our knowledge, no published data on transfusion requirement change in thalassemic patients supplemented with vitamin E exist. Therefore, it was estimated that 36 patients would be sufficient to test the hypothesis that the volume of transfused blood required would differ $20.0 \%$ between the patients taking vitamin $\mathrm{E}$ and those taking a placebo. This estimation was based on a two-sample normal approximation sample size formula, using an $80 \%$ power, a $95 \%$ confidence interval, a $5 \%$ significance level, and allowing for a dropout rate of up to $10 \%$ [University of California, Los Angeles, Department of Statistics (http:// calculators.stat.ucla.edu/powercalc/normal/n-2unequal/n-2-uneq-var-power.php)]

A random card shuffling was used to generate the random allocation sequences. The randomized lists were sent to the Pharmacy Department at Songklanagarind 
Hospital, Hat Yai, Thailand, in order to ensure that the concealment of the allocations was maintained. The trial medications (active and placebo) appeared identical and were dispensed into bottles. The patients, parents, pediatricians and all of the investigators were blinded to the treatment allocation. Moreover, the statisticians were blinded until recruitment had finished and the trial database closed.

The clinical assessments and blood collection took place at the time of randomization and every 3-4 weeks. At each visit, there was a documentation of the clinical characteristics, adverse events, medication compliance, and sizes of palpable liver and spleen below the costal margins, which were performed by two physicians. Blood was taken for a complete blood count (CBC) on every visit. The renal function test, direct antiglobulin test (DAT), and indirect antiglobulin test (IAT) were performed, and the hemolytic parameters and ferritin level were measured every 2 months, while the oxidative stress parameters and the antioxidant status were assessed at the time of recruitment and at the end of each period. The details of the laboratory methods followed have been previously described. ${ }^{19}$ As the reference values of vitamin $E$ in both adults and children are in the same range, ${ }^{20}$ normal healthy adults aged less than 45 years were selected as controls.

The data were analyzed using descriptive and inferential statistics. The differences in the continuous variables were compared using the paired T-test or the rank sum test ( $R$ software version 3.0.2). A p-value of $<0.05$ was considered statistically significant.

\section{Results}

There were 41 eligible patients, and 39 of them participated. Eighteen patients were randomly assigned to receive vitamin $\mathrm{E}$ first, while 21 started with placebo. One patient receiving the placebo died during the washout phase. Therefore, at the end of the study, there were 38 patients receive vitamin $\mathrm{E}$ and 39 receiving placebo (Figure 1). Their baseline characteristics are detailed in Table 1. There were 28 patients with hemoglobin $\mathrm{E} / \beta$ thalassemia and 11 patients with $\beta$-thalassemia major. Every patient was on an iron chelator, 26 patients on the oral form, 5 on the injected form, and 8 on a combined oral plus injected form.

During the period of supplementation, the volumes of transfused packed red cells ( \pm S.D.) required to maintain the same level as the baseline hemoglobin was 381.1 $( \pm 118.9)$ milliliters per visit while on vitamin $E$ and 367.2 ( \pm 113.6$)$ milliliters per visit during on placebo phase. There was no significant difference between the supplemental groups $(\rho=0.6)$, even after adjusting with an average of body weight in individual groups $(\rho=0.321)$. Likewise, there was no difference in confounding factors like number of occurrences of fever, number of positive antiglobulin tests (DAT, IAT), and also ferritin level that could affect our primary outcome (Table 2).

Vitamin E supplementation and its effects on the hemolytic parameters, size of liver and spleen, AST, LDH, reticulocyte count, and TB are shown in Table 2.

The vitamin E levels, the biochemical parameters that indicate oxidative stress and antioxidant status like the levels of MDA, GSH, GPx, and the SOD activity in the normal healthy subjects were within the reference ranges. At baseline, compared to the normal subjects, all of our patients had significantly lower levels of vitamin $E$ and GSH as well as higher levels of MDA, GPx and SOD activity. After a 6-month period to $200-400 \mathrm{mg}$ of daily vitamin $\mathrm{E}$ supplementation, the vitamin E level was normalized. Additionally, the GPx levels significantly decreased compared to those receiving the placebo. However, there was insignificant change in the levels of MDA, SOD and GSH after the vitamin E supplementation compared to placebo group (Table 3). 


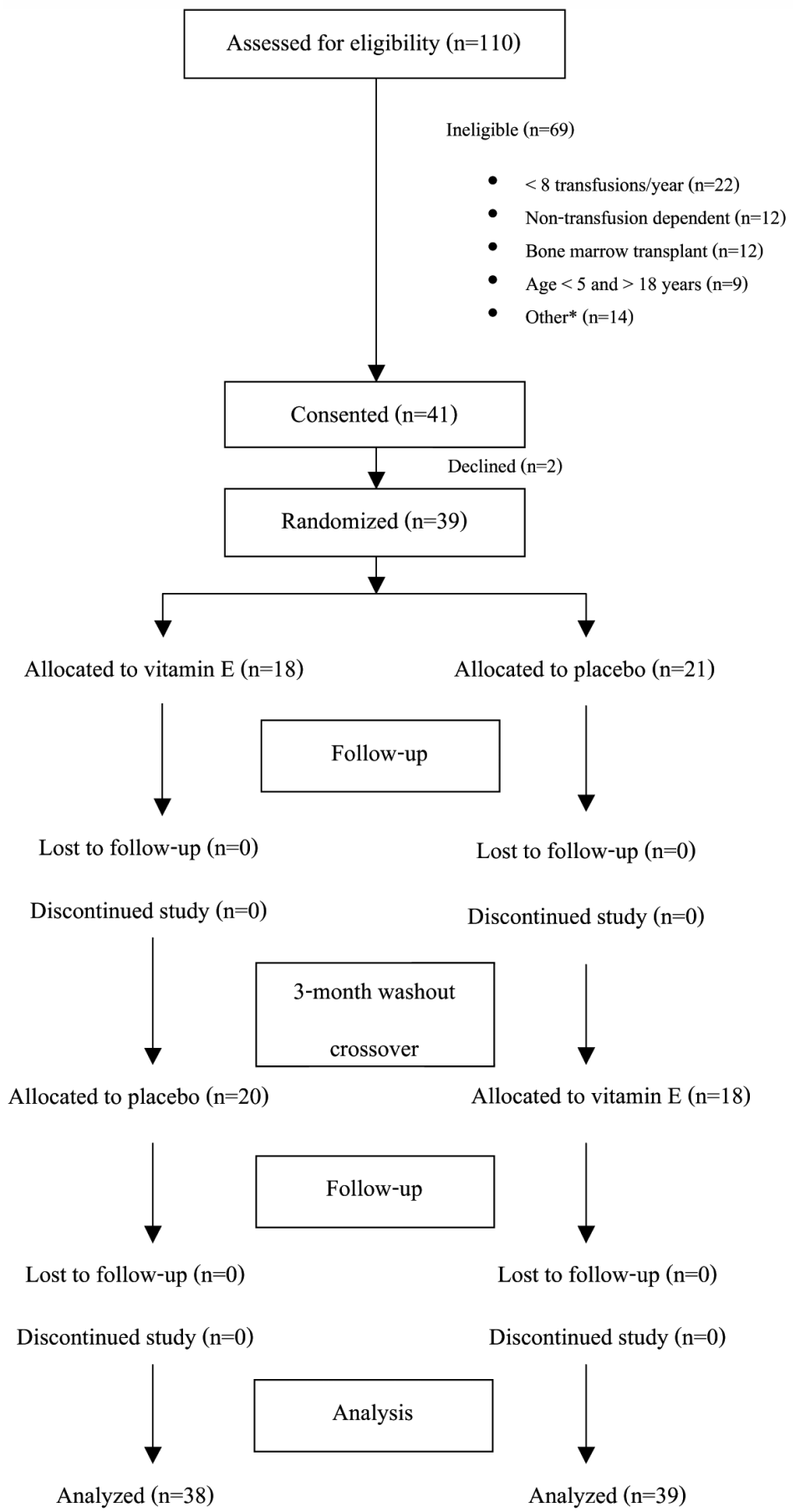

*Transfusion at other hospitals $n=8$; already part of another research $n=2$; diagnosed with abnormal hemoglobin $n=1$; diagnosed with hemoglobin $\mathrm{H}$ with hemoglobin Constant Spring disease $\mathrm{n}=2$; severe liver dysfunction $\mathrm{n}=1$

Figure 1 Allocation of patients 
Table 1 Baseline patient characteristics

\begin{tabular}{|c|c|}
\hline Characteristics & $\mathrm{N}=39$ \\
\hline Age (year); mean \pm S.D. & $11.95 \pm 3.91$ \\
\hline \multicolumn{2}{|l|}{ Gender (person); (\%) } \\
\hline Boy & $12(30.8)$ \\
\hline Girl & $27(69.2)$ \\
\hline Body weight $(\mathrm{kg})$; mean \pm S.D. & $30.7 \pm 10.4$ \\
\hline \multicolumn{2}{|l|}{ Type of $\beta$-thalassemia (person); (\%) } \\
\hline $\mathrm{Hb}$ E/ $\beta$-thalassemia & $28(71.8)$ \\
\hline$\beta$-thalassemia major & $11(28.2)$ \\
\hline Years of transfusion (year); mean \pm S.D. & $9.3 \pm 3.9$ \\
\hline \multicolumn{2}{|l|}{ Type of iron chelation (person); (\%) } \\
\hline Oral form & 26 \\
\hline Injection & 5 \\
\hline Combined & 8 \\
\hline Splenectomy (person); (\%) & $7(17.9)$ \\
\hline Pre-transfusion hemoglobin in the last 6 months $(\mathrm{g} / \mathrm{dL})$; mean \pm S.D. & $8.2 \pm 0.9$ \\
\hline Volume of blood transfusion in the last 6 months $(\mathrm{mL})$; mean $\pm S . D$. & $345.1 \pm 107.7$ \\
\hline Volume of blood transfusion per kilogram of body weight in the last 6 months $(\mathrm{mL} / \mathrm{kg})$; mean \pm S.D. & $11.4 \pm 1.4$ \\
\hline
\end{tabular}

S.D.=standard deviation

Table 2 Primary outcomes, hemolytic parameters and confounding factors in each period

\begin{tabular}{|c|c|c|c|}
\hline Parameter & $\begin{array}{l}\text { Vitamin E period } \\
(\mathrm{N}=38)\end{array}$ & $\begin{array}{l}\text { Placebo period } \\
(\mathrm{N}=39)\end{array}$ & P-value \\
\hline Hemoglobin (g/dL); median (IQR) & $8.4(7.8,8.8)$ & $8.6(7,7.9)$ & 0.492 \\
\hline Volumes of transfused PRCs $(\mathrm{mL})$; mean \pm S.D. & $381.1 \pm 118.9$ & $367.2 \pm 113.6$ & 0.6 \\
\hline $\begin{array}{l}\text { Volumes of transfused PRCs per kilogram of body weight }(\mathrm{mL} / \mathrm{kg}) \\
\text { mean } \pm \text { S.D. }\end{array}$ & $11.8 \pm 2.0$ & $11.3 \pm 1.7$ & 0.321 \\
\hline Liver size below right costal margin $(\mathrm{cm})$; median (IQR) & $4(3.5,4.8)$ & $4.2(3.4,4.7)$ & 0.695 \\
\hline Splenic size below left costal margin $(\mathrm{cm})$; median (IQR) & $5(3.1,7.5)$ & $5.1(3.2,7.3)$ & 0.953 \\
\hline Fever (times); (\%) & $19(5.8)$ & $20(5.8)$ & 1 \\
\hline Reticulocyte count (\%); median (IQR) & $2.7(1.9,4.5)$ & $2.5(1.9,4.8)$ & 0.791 \\
\hline TB (mg \%); median (IQR) & $1.6(1.3,2.2)$ & $1.7(1.3,2.6)$ & 0.514 \\
\hline AST (U/); median (IQR) & $31.2(22.2,47.1)$ & $33.2(26.1,43.5)$ & 0.479 \\
\hline LDH (U/); median (IQR) & $548.4(450.8,663.6)$ & $543.5(472.5,678.3)$ & 0.718 \\
\hline Ferritin (ng/mL); median (IQR) & $2432.2(1583.4,3282.8)$ & $2578.2(1761.2,3126.6)$ & 0.524 \\
\hline Positive antiglobulin test (person); (\%) & $15(39.50)$ & $9(23.1)$ & 0.191 \\
\hline
\end{tabular}

IQR=interquartile range, S.D.=standard deviation, PRC=packed red cell, TB=total bilirubin, $\mathrm{LDH}=$ lactate dehydrogenase,

$\mathrm{AST}=$ aspartate transaminase 


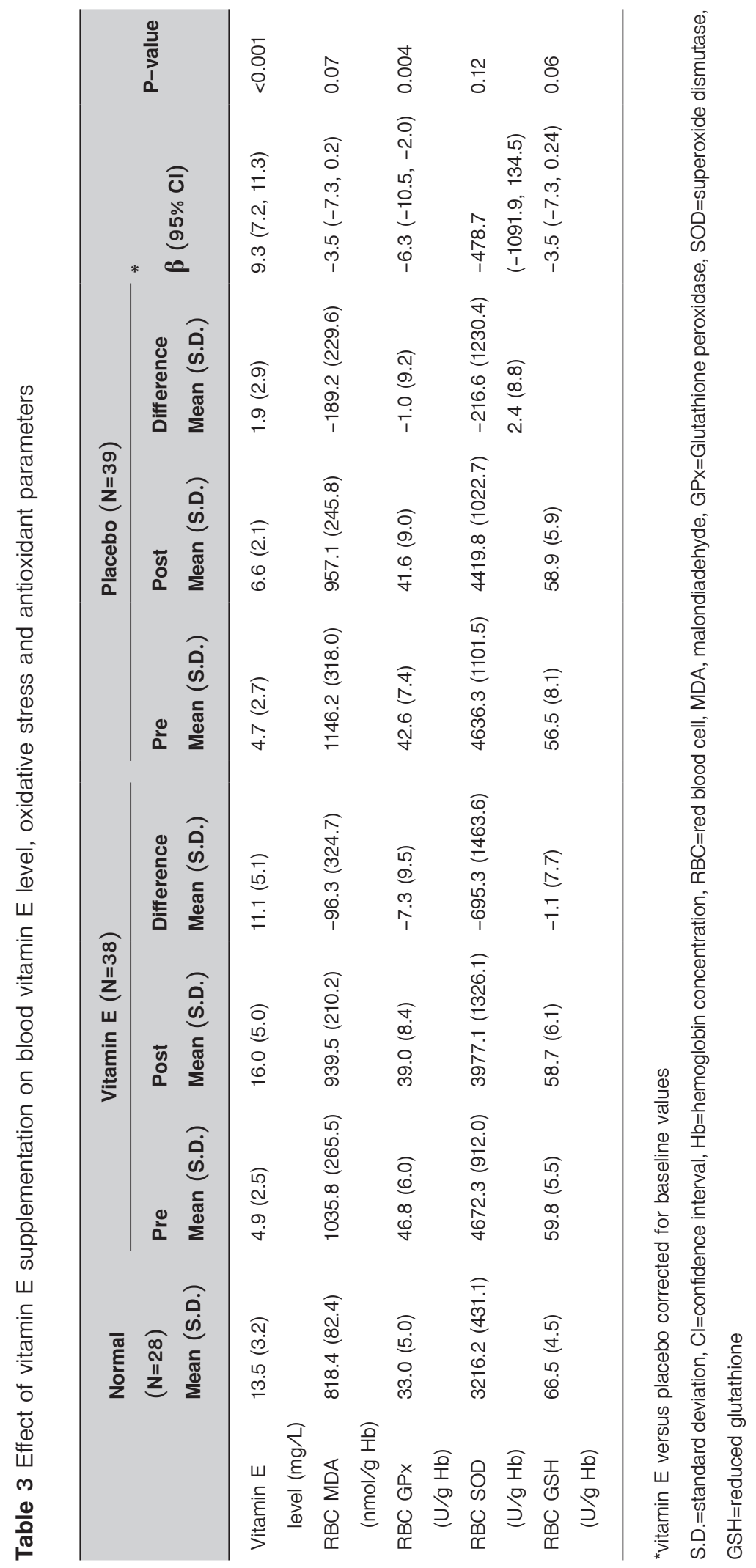


No adverse reactions were found in the 15-month study period, but two serious adverse events happened. One patient developed gall stones with acute cholecystitis and acute pancreatitis, and another died during the washout phase at home with an unknown cause of death. All that was known to us was that she had fever for a week, but her parents did not seek medical attention.

\section{Discussion}

The strength of this study is that it is the largest and perhaps the first, prospective, double-blind, randomized, placebo-controlled, crossover study of the role of vitamin E supplementation in children with $\beta$-thalassemia on the volumes of transfused packed red cells; thus, it provides the best evidence available regarding the evaluation of this treatment. In an earlier study involving 9 patients that was conducted by Rachmilewitz in $1982,{ }^{18}$ no significant changes occurred in hemoglobin levels and in transfusion requirements after $750-1,000 \mathrm{mg}$ of vitamin $\mathrm{E}$ was taken daily for 5-7 months. However, that study was only a case series, which was not randomized, did not involve a control group, and was performed in patients aged 15-30 years.

The present study of 39 children with $\beta$-thalassemia major and $\mathrm{Hb}$ E/ $\beta$-thalassemia disease demonstrated that they had low vitamin E levels, high oxidative stress, and antioxidant deficiency. However, vitamin-E supplementation was not associated with any benefit in reducing the volumes of transfused packed red cells required to maintain the hemoglobin level to the baseline compared with the placebo although the levels of vitamin $\mathrm{E}$ were normalized after a 6-month period of taking 200-400 mg of vitamin $\mathrm{E}$ supplementation daily. Vitamin $E$ is one of the important antioxidants for lipid peroxidation and metabolic change in thalassemia patients, and in this study, the mean level of serum vitamin $E$ was 2.7 times lower in our patients than in the healthy control subjects. This finding is comparable to those of previous studies that have reported levels of serum vitamin E 3 times lower in thalassemia patients compared to normal subjects. ${ }^{16,17}$ Theoretically, the normalization of vitamin $E$ level could account for a decrease in the level of lipid peroxidation products and membrane damage, and consequently, a decrease in the percentage of erythrocyte hemolysis. ${ }^{21}$ Therefore, volumes of transfused packed red cells and the hemolytic parameter values of size of liver and spleen, AST, LDH, reticulocyte count and TB should be lower. However, this study failed to prove this assumption. Although vitamin E levels elevated 3.3-fold and returned to the normal range, all of the measured hemolytic parameters and also the volumes of blood transfused experienced no significant changes. Even though there was a significant improvement in terms of GPx after vitamin E supplementation compared to the placebo, all of the measured excessive oxidative stress parameters such as the levels of MDA, GSH, GPx and SOD activity did not be normalize. Dissayabutra ${ }^{17}$ found an insignificant decrease in TB level after a 3-month period of taking a combination of $100 \mathrm{mg}$ per day of vitamin C, $400 \mathrm{mg}$ of vitamin $\mathrm{E}$ in patients weighing less than $20 \mathrm{~kg}$, and $600 \mathrm{mg}$ of vitamin $\mathrm{E}$ in patients weighing at least $20 \mathrm{~kg}$. This may be due to the higher dose of vitamin $\mathrm{E}$ and the combined effect of vitamin $\mathrm{C}$ on TB.

Oxidative damage in $\beta$-thalassemia patients results from the accumulation of unpaired $\alpha$-globin and iron overload, causing cell injury and hemolysis. ${ }^{19}$ The increased peroxidative damage is supported by the increased level of MDA content and a marked decrease in antioxidants such as vitamin $\mathrm{E}$ and $\mathrm{GSH} .{ }^{9-13}$ The antioxidant status can also be investigated by the direct measurement of cytoprotective enzymes such as SOD and GPx activities inside RBCs, and both of their levels have been reported to be significantly increased. ${ }^{19}$ Our findings confirmed the results of the above-mentioned studies. In comparison to controls, this study showed a significantly lower GSH level but higher levels of MDA, GPx and SOD activity in $\beta$-thalassemia 
major and $\mathrm{Hb} E / \beta$-thalassemia disease patients ( $p$-value $<$ 0.001).

A high variation in the dosage of vitamin $E$ supplementation for thalassemia patients exists in literature. ${ }^{17,18,21}$ We chose the dosage of $10 \mathrm{mg}$ per $\mathrm{kg}$ daily, which is around ten times higher than the normal daily requirement, but it does not exceed the tolerated dose. $^{22}$ With this dosage, we managed to correct the serum level of vitamin $\mathrm{E}$, but the oxidative stress remained high. This could be due to the persistent high iron overload in our patients, so vitamin E alone was insufficient to overcome all of the oxidative stress. A study of a combined menu of vitamin $E$ with other potent antioxidants showed beneficial effects on oxidative stress, hemoglobin concentration and hypercoagulable state in adult non-transfusion dependent $\beta$-thalassemia/Hb E patients. ${ }^{23}$

The limitation of this study was its small sample size. Many potential patients were determined ineligible in the enrollment process, mainly due to their non- or lowtransfusion status. Meanwhile, some others were undergoing stem cell transplantation.

\section{Conclusion}

Our $\beta$-thalassemia major and $\mathrm{Hb} \mathrm{E} / \beta$-thalassemia patients were in a state of enhanced oxidative stress and vitamin E deficiency. Moreover, the daily supplementation with a $200-400 \mathrm{mg}$ per day of vitamin $\mathrm{E}$ for a 6-month period normalized the vitamin E level, but it failed to correct the oxidative damage. Finally, no differences in the volumes of transfusion requirement and hemolytic parameters were observed.

\section{References}

1. Forget BG, Bunn HF. Classification of the disorders of hemoglobin. Cold Spring Harb Perspect Med 2013;3:a011684.

2. Panich V, Pornpatkul M, Sriroongrueng W. The problem of thalassemia in Thailand. Southeast Asian J Trop Med Public Health 1992;23:1-6
3. Martin A, Thompson AA. Thalassemias. Pediatr Clin N Am 2013; 1383-91.

4. Cappellini MD, Cohen A, Porter J, Taher A, Viprakasit V. Guidelines for the management of transfusion dependent thalassemia (TDT). $3^{\text {rd }}$ ed. Nicosia: Thalassaemia International Federation, 2014.

5. Fucharoen S, Winichagoon P. Haemoglobinopathies in Southeast Asia. Indian J Med Res 2011;134:498-506.

6. Tavazzi D, Duca L, Graziadei G, Comino A, Fiorelli G, Cappellini MD. Membrane-bound iron contributes to oxidative damage of beta-thalassaemiaintermedia erythrocytes. $\mathrm{Br} \mathrm{J}$ Haematol 2001;112:48-50.

7. Advani R, Sorenson S, Shinar E, Lande W, Rachmilewitz E, Schrier SL. Characterization and comparison of the red blood cell membrane damage in severe human alpha-and betathalassemia. Blood 1992;79:1058-63.

8. Rund D, Rachmilewitz E. Beta-thalassemia. N Engl J Med 2005;353:1135-46.

9. Ghone RA, Kumbar KM, Suryakar AN, Katkam RV, Joshi NG. Oxidative stress and disturbance in antioxidant balance in beta thalassemia major. Indian Clin Biochem 2008;23:337-40.

10. Naithani R, Chandra J, Bhattacharjee J, Verma P, Narayan S. Peroxidative stress and antioxidant enzymes in children with beta-thalassemia major. Pediatr Blood Cancer 2006;46:780-5.

11. Das N, Das Chowdhury T, Chattopadhyay A, Datta AG. Attenuation of oxidative stress-induced changes in thalassemic erythrocytes by vitamin E. Pol J Pharmacol 2004;56:85-96.

12. Cighetti G, Duca L, Bortone L, Sala S, Nava I, Fiorelli G, et al. Oxidative status and malondialdehyde in beta-thalassaemia patients. Eur J Clin Invest 2002;32:55-60.

13. Kassab-Chekir A, Laradi S, Ferchichi S, Haj Khelil A, Feki M, Amri $\mathrm{F}$, et al. Oxidant, antioxidant status and metabolic data in patients with beta-thalassemia. Clin Chim Acta 2003;338: 79-86.

14. Chakraborty D, Bhattacharyya M. Antioxidant defense status of red blood cells of patients with $\beta$-thalassemia and $E$ $\beta$-thalassemia. Clin Chim Acta 2001;305:123-9.

15. Brigelius-Flohe R, Traber MG. Vitamin E: function and metabolism. Faseb J 1999;13:1145-55.

16. Dhawan V, Kumar KhR, Marwaha RK, Ganguly NK. Antioxidant status in children with homozygous thalassemia. Indian Pediatr 2005;42:1141-5 
17. Dissayabutra $T$, Tosukhowong $P$, Seksan $P$. The benefits of vitamin $\mathrm{C}$ and vitamin $\mathrm{E}$ in children with beta-thalassemia with high oxidative stress. J Med Assoc Thai 2005;88(Suppl 4): S317-21.

18. Rachmilewitz EA, Kornberg A, Acker M. Vitamin E deficiency due to increased consumption in beta-thalassemia and in Gaucher's disease. Ann N Y Acad Sci 1982;393:336-47.

19. Kalpravidh RW, Siritanaratkul N, Insain P, Charoensakdi R, Panichkul N, Hatairaktham S, et al. Improvement in oxidative stress and antioxidant parameters in beta-thalassemia/Hb E patients treated with curcuminoids. Clin Bio Chem 2010;43: 424-9.

20. Traber MG. Vitamin E. In: Shils ME, Shike M, Ross A, Caballero $\mathrm{B}$, Cousins R, editors. Modern nutrition in health and disease. $10^{\text {th }}$ ed. Baltimore: Lippincott Williams and Wilkins; 2006; p.434-41.

21. Attia MMA, Sayed AM, Ibrahim FA, Mohammed AS, El-Alfy MS. Effects of antioxidant vitamins on some hemoglobin properties and erythrocytes in homozygous beta-thalassemia. Rom J Biophys 2011;21:93-106.

22. Traber MG, Manor D. Vitamin E. Adv Nutr 2012;3:330-1

23. Yanpanitch O, Hatairaktham S, Charoensakdi R, Panichkul N, Fucharoen S, Srichairatanakool $S$, et al. Treatment of $\beta$-thalassemia/hemoglobin $E$ with antioxidant cocktails results in decreased oxidative stress, increased hemoglobin concentration and improvement of the hypercoagulable state. Oxid Med Cell Longev 2015;2015:537954. DOI: 10.1155/2015/537954. 